\title{
Analisis Efek Tapak Lokal pada Lokasi Stasiun Seismik di Pulau Jawa
}

\author{
Sesar Prabu Dwi Sriyanto ${ }^{1, *}$ dan Indri Ifantyana ${ }^{2}$ \\ ${ }^{1}$ Stasiun Geofisika Manado, Jl. Harapan 42 Manado, Sulawesi Utara, 95161 \\ ${ }^{2}$ Pusat Gempabumi dan Tsunami, BMKG, Jl. Angkasa I no. 2, Kemayoran, Jakarta Pusat 10270
}

Intisari

Salah satu syarat penempatan stasiun seismik yang baik yaitu sensor seismik harus diletakkan di atas batuan dasar dengan tujuan untuk meminimalisir faktor amplifikasi gelombang yang berpengaruh pada penentuan magnitudo gempabumi. Pada penelitian ini dilakukan analisis karakteristik tanah lokasi sensor seismik pada 22 stasiun seismik yang tersebar di Pulau Jawa. Data sinyal seismogram getaran natural dari masing-masing stasiun dianalisis menggunakan metode Horizontal to Vertical Spectral Ratio (HVSR) untuk mendapatkan nilai faktor amplifikasi (Ao) dan periode dominan (Tdom) tanah. Untuk penentuan jenis tanah di lokasi stasiun seismik, digunakan nilai periode dominan (Tdom) tanah. Dari 22 stasiun seismik, sejumlah 36,4\% berlokasi pada tanah lunak, $13,6 \%$ pada tanah medium, 22,7\% pada tanah keras, dan $27,27 \%$ terletak pada batuan. Sejumlah 10 stasiun seismik memiliki faktor amplifikasi lebih dari 2 kali lipat, dengan nilai tertinggi 7,73 kali pada stasiun CNJI (Cianjur, Jawa Barat) dan nilai terendah 0,89 pada stasiun TNGI (Tangerang, Banten). Tidak hanya efek tapak lokal namun perlakuan terhadap sensor juga mempengaruhi nilai amplifikasi gelombang di stasiun.

\begin{abstract}
One of the specification of good seismic station placement is the seismic sensor which should be placed on the bedrock to minimize the wave amplification factor that affect to the earthquake magnitude calculation. In this study, we analyze the soil characteristics in the seismic sensor location at 22 seismic stations placed in Java island. Seismogram data, which is free from seismic noise, from each station were analyzed using Horizontal to Vertical Spectral Ratio (HVSR) method to get the value of the soil amplification factor (Ao) and the dominant period (Tdom). To determine the type of soil at the seismic station location, we used the dominant period (Tdom). The result, $36.4 \%$ are located on soft soil, $13.6 \%$ on the medium soil type, $22.7 \%$ on the hard soil type, and $27.27 \%$ lies in the soil class I, which is a rock. The 10 seismic stations has the amplification factor more than 2.0, with the highest value is 7.73 at CNJI station (Cianjur, West Java Province) and the lowest value is 0.89 at TNGI station (Tangerang, Banten Province). Not only the local site effect but the treatment of the sensor also affects the seismic wave amplification at the stations.
\end{abstract}

KATA KUNCI: seismic station, amplification factor, soil classification http://dx.doi.org/10.12962/j24604682.v14i3.3845

\section{PENDAHULUAN}

Jaringan stasiun seismik sangat diperlukan untuk mendeteksi dan memantau kejadian gempabumi. Dari sensor seismik yang telah terpasang di berbagai lokasi, kita dapat memperoleh hasil catatan sinyal gempabumi. Jika hasil catatan sinyal ini dianalisis lebih lanjut maka akan didapatkan parameter-parameter gempabumi meliputi origin time, magnitudo, lokasi episenter, kedalaman, dan mekanisme sumbernya. Untuk itu, penempatan sensor seismik pada jaringan stasiun seismik harus sesuai dengan prosedur penempatan sensor yang baik. Salah satu syarat penempatan stasiun seismik yang baik yaitu sensor seismik diletakkan di atas batuan dasar (bedrock). Hal ini dilakukan untuk meminimalisir faktor amplifikasi gelombang gempabumi [1].

Amplifikasi gelombang adalah menguatnya amplitudo

\footnotetext{
*E-MAIL: sesar.sriyanto@bmkg.go.id
}

gelombang karena efek tapak lokal, dimana tanah yang relatif lunak akan menghasilkan amplitudo getaran gempa yang lebih besar jika dibandingkan tanah yang relatif keras. Faktor amplifikasi memberikan gambaran pembesaran percepatan gerakan tanah dari batuan dasar ke permukaan [2]. Besarnya nilai amplifikasi di setiap lokasi dapat bervariasi bergantung pada tingkat kekakuan batuan [3].

Penempatan sensor seismik stasioner untuk monitoring gempabumi di Pulau Jawa berlokasi pada jenis tanah yang berbeda-beda dan memiliki efek tapak lokal yang berbeda pula. Faktor amplifikasi pada jaringan stasiun seismik yang berbeda-beda sangat berpengaruh pada penentuan magnitudo, terutama magnitudo lokal. Jenis magnitudo lokal sangat dibutuhkan untuk menentukan magnitudo gempa-gempa mikro yang hanya terekam pada stasiun skala lokal [4]. Oleh karena itu, informasi nilai faktor amplifikasi pada masing-masing stasiun seismik dibutuhkan untuk mencari nilai koreksi amplifikasi.

Pada penelitian ini, analisis karakteristik tanah pada lokasi peletakan 22 sensor seismik stasioner yang tersebar di Pulau 


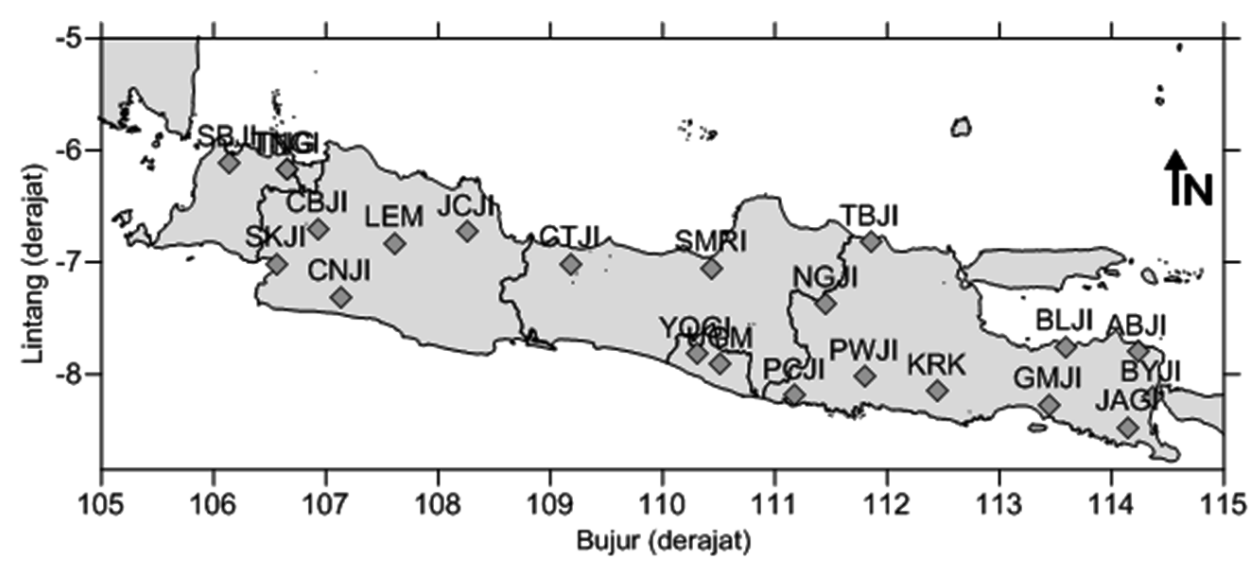

Gambar 1: Sebaran 22 stasiun seismik yang dianalisis.

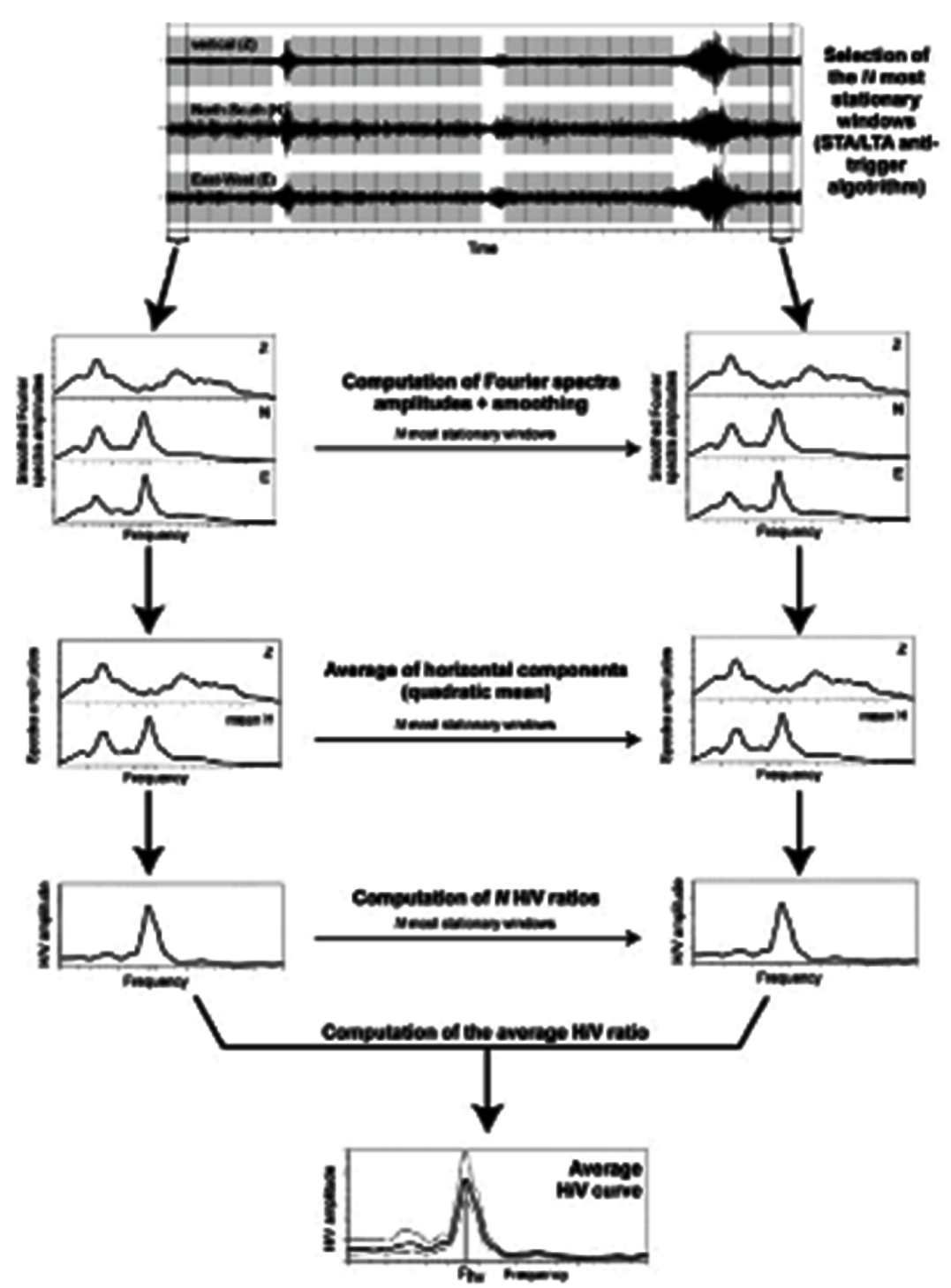

Gambar 2: Tahapan pengolahan data mikrotremor dengan metode HVSR [5]. 
TABEL I: Klasifikasi kelas tanah berdasarkan rentang nilai periode dominan dan Vs30 [9]

\begin{tabular}{llcl}
\hline \hline $\begin{array}{l}\text { Kelas } \\
\text { Tanah }\end{array}$ & Deskripsi & $\begin{array}{c}\text { Periode } \\
\text { Dominan (s) }\end{array}$ & Vs30 (km/s) \\
\hline Kelas Tanah I & Batu & $\mathrm{T}<0,2$ & Vs30 $>600$ \\
Kelas Tanah II & Tanah keras & $0,2 \leq \mathrm{T}<0,4$ & $300<$ Vs $30 \leq 600$ \\
Kelas Tanah III & Tanah medium & $0,4 \leq \mathrm{T}<0,6$ & $200<$ Vs $30 \leq 300$ \\
Kelas Tanah IV Tanah lunak & $0,6 \leq \mathrm{T}$ & Vs30 $\leq 200$ \\
\hline \hline
\end{tabular}

TABEL II: Nilai periode dominan, faktor amplifikasi, dan klasifikasi tanah lokasi masing-masing stasiun seismik

\begin{tabular}{lccccc}
\hline Stasiun Lintang $\left(^{\circ}\right)$ & Bujur $\left(^{\circ}\right)$ & Tdom $(s)$ & Ao & Kelas Tanah \\
\hline PWJI & $-8,02$ & 111,8 & 0,1012 & 1,9944 & I \\
SMRI & $-7,05$ & 110,44 & 0,1185 & 2,5652 & I \\
PCJI & $-8,19$ & 11,18 & 0,1393 & 1,4246 & I \\
CNJI & $-7,31$ & 107,13 & 0,1424 & 7,7339 & I \\
BYJI & $-8,21$ & 114,36 & 0,1462 & 4,9211 & I \\
UGM & $-7,91$ & 110,52 & 0,1844 & 1,404 & I \\
JCJI & $-6,73$ & 108,26 & 0,2247 & 2,9824 & II \\
GMJI & $-8,27$ & 113,44 & 0,2345 & 1,9026 & II \\
TBJI & $-6,82$ & 111,85 & 0,254 & 1,1041 & II \\
KRK & $-8,15$ & 112,45 & 0,2547 & 4,3082 & II \\
YOGI & $-7,82$ & 110,3 & 0,3634 & 1,0052 & II \\
LEM & $-6,83$ & 107,62 & 0,4084 & 3,1112 & III \\
SKJI & $-7,01$ & 106,56 & 0,4773 & 2,6748 & III \\
CBJI & $-6,7$ & 106,93 & 0,5347 & 7,2141 & III \\
JAGI & $-8,47$ & 114,15 & 0,6949 & 1,4914 & IV \\
CTJI & $-7,01$ & 109,18 & 1,0782 & 2,1809 & IV \\
BLJI & $-7,75$ & 113,59 & 1,1775 & 2,2562 & IV \\
TNG & $-6,17$ & 106,65 & 1,2073 & 1,8584 & IV \\
TNGI & $-6,17$ & 106,65 & 1,2102 & 0,89 & IV \\
NGJI & $-7,37$ & 111,46 & 1,2423 & 1,4119 & IV \\
SBJI & $-6,11$ & 106,13 & 1,2781 & 1,6567 & IV \\
ABJI & $-7,8$ & 114,23 & 1,5838 & 1,1356 & IV \\
\hline \hline
\end{tabular}

Jawa dilakukan untuk mengetahui frekuensi natural getaran tanah (fo), periode dominan (Tdom), serta faktor amplifikasi (Ao). Parameter-parameter tanah tersebut dapat digunakan untuk mengetahui karakteristik tanah permukaan pada lokasi penempatan sensor.Selain itu, parameter ini juga berguna untuk koreksi pada data gempabumi agar parameter gempabumi yang dihasilkan lebih akurat.

\section{DATA DAN METODE}

Dari 39 stasiun seismik yang tersebar di Pulau Jawa, dipilih 22 stasiun seismik yang dinilai memiliki data seismogram baik. Pada Gambar 1. ditunjukkan peta sebaran stasiun seismik yang dianalisis. Data sinyal seismogram diperoleh dari webdc3 BMKG. Untuk mendapatkan sinyal getaran natural yang terbebas dari bising lingkungan, dipilih data sinyal pada waktu dini hari yang dianggap sebagai waktu tenang. Data tersebut kemudian diolah dengan metode HVSR (Horizontal to Vertical Spectral Ratio).
HVSR adalah metode untuk memperhitungkan rasio amplitudo spektrum komponen horizontal dan komponen vertikal mikrotremor yang direkam di salah satu stasiun. Secara umum, konsep HVSR adalah adanya suatu kesamaan antara rasio spektra horizontal ke vertikal dengan transfer gelombang dari batuan dasar ke permukaan. Periode dominan dan nilai puncak dari spektra rasio (H/V) mempunyai kesamaan dengan periode natural dan faktor amplifikasi dari lapisan tanah [5]. Nilai H/V diperoleh dari perbandingan antara spektrum amplitudo Fourier komponen gelombang horizontal terhadap gelombang vertikal [2].

Proses awal dari metode HVSR adalah memilih sinyal mikrotremor yang terbebas dari bising. Selanjutnya dilakukan Transformasi Fourier Cepat (Fast Fourier Transform) untuk melihat spektrum sinyal mikrotremor dalam domain frekuensi. Jika variasi data random sebagai fungsi waktu adalah $\mathrm{f}(\mathrm{k})$ maka transformasi Fourier dirumuskan sebagai berikut [6]:

$$
f(n)=\sum_{k=0}^{N-1}\left(f(k) W^{\frac{n k}{N}}\right)
$$

dengan $\mathrm{f}(\mathrm{n})$ dan $\mathrm{f}(\mathrm{k})$ secara berurutan merupakan amplitudo frekuensi ke-n dan ke-k, $\mathrm{k}$ dan $\mathrm{n}$ ialah indeks frekuensi dan indeks data, sedangkan $\mathrm{N}$ mendeskripsikan jumlah data. Selain itu juga dideskripsikan bahwa :

$$
W=e^{\frac{-i 2 \pi}{N}}=\cos \left(\frac{2 \pi}{N}\right)-i \sin \left(\frac{2 \pi}{N}\right)
$$

Selanjutnya dilakukan smoothing pada hasil FFT tersebut menggunakan metode Konno-Omachi dengan koefisien bandwith 40 [7, 8], kemudian dihitung rasio komponen horizontal (hasil resultan komponen $\mathrm{N}-\mathrm{S}$ dan $\mathrm{E}-\mathrm{W}$ ) terhadap komponen vertikal.

$$
H V S R=\frac{\sqrt{E W(\omega)^{2}+N S(\omega)^{2}}}{U D(\omega)}
$$

Dari kurva HVSR dalam domain frekuensi dapat dilihat bahwa nilai respon spektra maksimum merupakan nilai faktor amplifikasi tanah (Ao) sedangkan nilai frekuensi pada respon spektra maksimum merupakan nilai frekuensi dominan tanah (fo). Nilai periode dominan tanah (Tdom) didapat dari rumusan berikut:

$$
T d o m=\frac{1}{f_{o}}
$$

Setelah tahapan pengolahan data mikrotremor dengan metode HVSR seperti pada Gambar 2 selesai, selanjutnya dilakukan penentuan klasifikasi jenis tanah berdasarkan nilai periode dominan getaran tanah yang didasarkan pada Tabel I tentang klasifikasi kelas tanah [9].

\section{HASIL DAN PEMBAHASAN}

Hasil pengolahan sinyal masing-masing stasiun dengan metode HVSR berupa nilai frekuensi dominan getaran tanah 


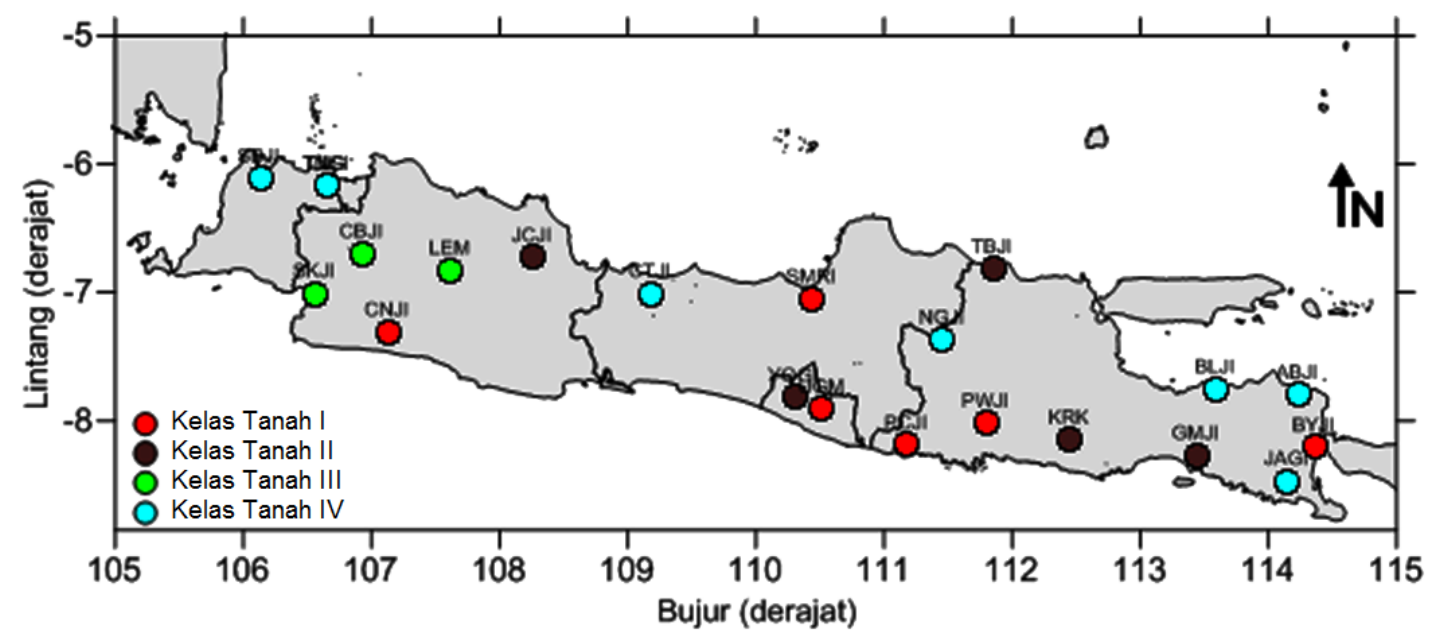

Gambar 3: Sebaran 22 stasiun seismik dengan keterangan kelas tanah lokasi stasiun.

dan nilai amplitudo respon spektra maksimum yang didefinisikan sebagai nilai faktor amplifikasi. Nilai periode dominan yang nilainya berbanding terbalik dengan frekuensi dominan tersebut dipengaruhi oleh kecepatan gelombang geser dan ketebalan lapisan sedimen di lokasi sensor [3]. Pada Tabel II ditunjukkan nilai periode dominan, faktor amplifikasi, dan kelas tanah lokasi penempatan sensor seismik, sedangkan pada Gambar 3 ditunjukkan sebaran 22 stasiun seismik dengan keterangan kelas tanah lokasi stasiun.

Dari hasil analisis dapat diketahui bahwa sebagian besar stasiun seismik terletak pada kelas tanah IV yang dideskripsikan sebagai tanah lunak. Sejumlah $36,4 \%$ atau 8 dari 22 stasiun memiliki nilai periode dominan lebih dari 0,6 detik. Stasiun ABJI yang terletak di Situbondo, Jawa Timur memiliki nilai periode dominan tertinggi sebesar 1,58 detik. Hal ini mengindikasikan bahwa stasiun ABJI dan 7 stasiun lainnya berlokasi pada jenis tanah lunak.

Stasiun seismik yang berlokasi di atas batuan dasar ada 6 stasiun yaitu PCJI, CNJI, SMRI, PWJI, UGM, dan BYJI. Stasiun PWJI yang terletak di Tulungagung, Jawa Timur memiliki nilai periode dominan terendah pada nilai 0,1012 detik. Sejumlah 2 dari 6 stasiun tersebut (UGM dan PCJI) terletak dalam kompleks Geopark Gunung Sewu dengan kondisi geologi berupa batuan karst, dimana tipe batuannya keras dan sedikit tertutup sedimen sehingga sangat baik untuk penempatan sensor seismik.

Kelas tanah II dengan rentang nilai Tdom 0,2 hingga 0,4 detik memiliki jenis tanah yang keras. Sebanyak 22,72\% dari 22 stasiun tersebut terletak pada jenis tanah ini. Stasiun-stasiun tersebut adalah JCJI, GMJI, TBJI, KRK, dan YOGI. Lokasi penempatan stasiun seismik pada kelima stasiun ini berada pada daerah perbukitan yang memiliki lapisan sedimen tipis sehingga masih cocok untuk penempatan stasiun seismik.

Stasiun seismik Lembang (LEM), Sukabumi (SKJI), dan Citeko (CBJI) terletak pada tanah dengan jenis kelas tanah III dimana berupa tanah medium (medium soil). Stasiun yang seluruhnya terletak di Propinsi Jawa Barat ini berada pada daerah dataran tinggi yang masih memiliki lapisan sedimen. Rentang nilai periode dominan dari ketiga stasiun ini adalah

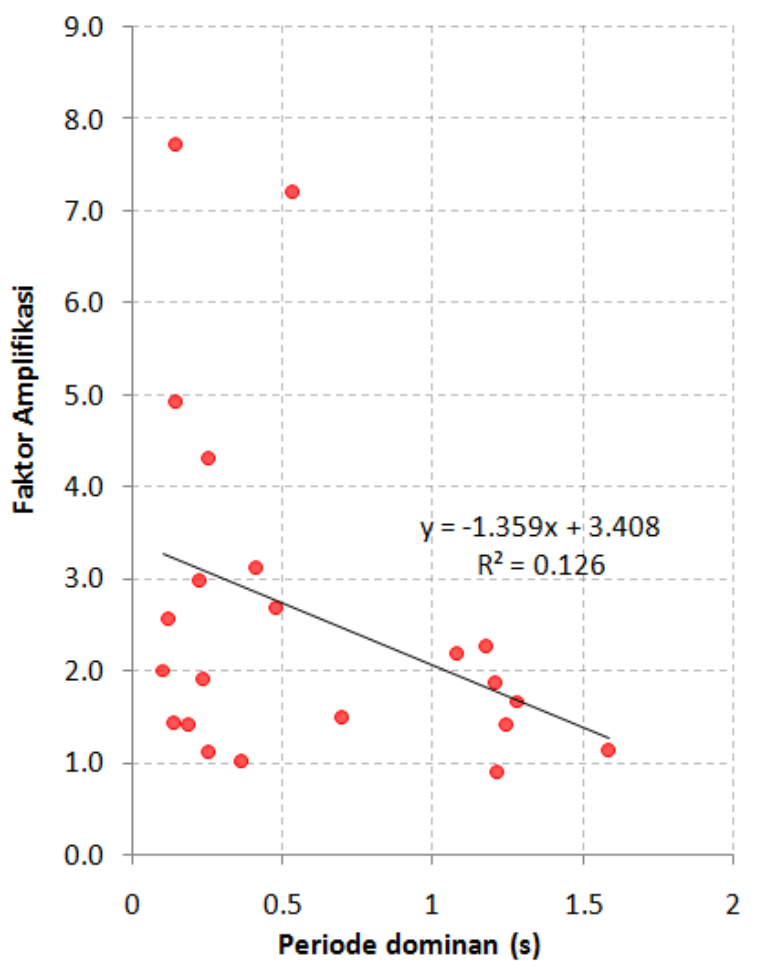

Gambar 4: Grafik hubungan antara periode dominan dengan faktor amplifikasi.

0,4084 hingga 0,5347 detik.

Tabel II menunjukkan bahwa sebagian besar rekaman stasiun seismik yang dianalisis mengalami amplifikasi. Rentang nilai amplifikasi dari stasiun-stasiun yang dianalisis adalah 0,89 hingga 7,7339. Nilai amplifikasi tinggi terjadi di stasiun CNJI dan CBJI dengan amplifikasi mencapai 7,0. Amplifikasi tinggi juga terjadi pada sensor BYJI, KRK, LEM, JCJI, SKJI, SMRI, BLJI, dan CTJI yang memiliki nilai faktor amplifikasi diatas 2,00, sedangkan 12 stasiun lainnya memiliki nilai faktor amplifikasi dibawah 2,00. 


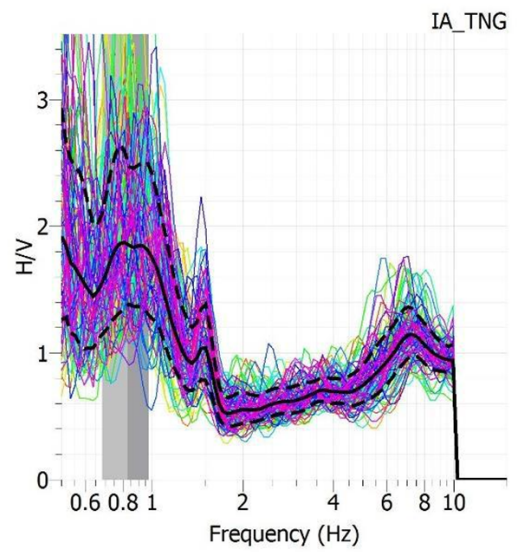

(a)

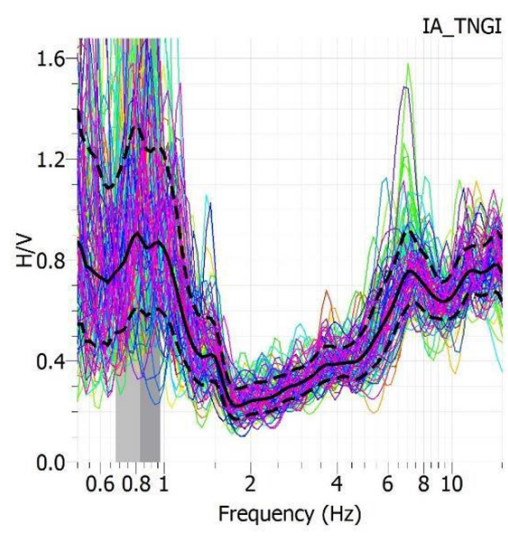

(b)

Gambar 5: Kurva HVSR (a) sensor TNG dan(b) sensor TNGI.

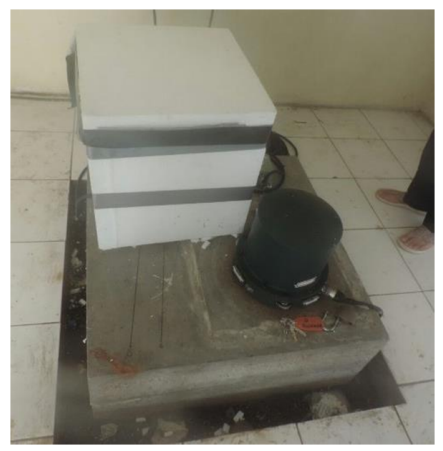

Gambar 6: Penempatan sensor TNG dan TNGI dengan perlakuan berbeda. Sensor TNGI dimasukkan dalam kotak styrofoam sedangkan sensor TNG tidak dimasukkan dalam kotak.
Nilai periode dominan dan faktor amplifikasi diplot dalam grafik pada Gambar 4. Dari grafik periode dominan versus faktor amplifikasi tidak menunjukkan adanya hubungan yang linier antara keduanya. Hal ini terjadi karena nilai faktor amplifikasi tidak hanya dipengaruhi oleh jenis tanah permukaan dan ketebalan sedimen, namun variasi parameter sedimen (modulus geser, rasio redaman, dan densitas) dan saturasi lapisan sedimen juga mempengaruhi faktor amplifikasi gelombang $[10,11]$.

Penelitian ini menunjukkan bahwa perlakuan terhadap sensor diperkirakan juga mempengaruhi nilai faktor amplifikasi. Sensor TNG dan TNGI yang ditempatkan dalam satu shelter (collocated) di Tangerang, Banten memiliki nilai amplifikasi yang berbeda namun nilai frekuensi dominan sama. Kurva HVSR sensor TNG dan TNGI pada Gambar 5 menunjukkan bahwa nilai amplifikasi pada sensor TNG yang bernilai 1,8584 lebih tinggi daripada nilai amplifikasi pada sensor TNGI yang bernilai 0,89 . Sensor TNGI yang dimasukkan dalam kotak styrofoam diperkirakan mengalami redaman gelombang komponen horizontal sehingga memiliki nilai amplifikasi lebih rendah daripada sensor TNG yang tidak dimasukkan dalam kotak, seperti yang ditunjukkan pada Gambar 6. Perlakuan berbeda pada sensor collocated ini tidak berpengaruh pada nilai frekuensi dominan dan bentuk kurva HVSR sehingga nilai frekuensi dominan dapat dijadikan sebagai acuan untuk pengklasifikasian tanah permukaan pada lokasi penempatan sensor seismik.

\section{SIMPULAN}

Dari 22 stasiun seismik yang digunakan untuk memonitoring aktivitas gempabumi di Pulau Jawa, sebagian besar berlokasi pada tanah lunak. Sementara itu, stasiun seismik yang memiliki faktor amplifikasi tinggi hingga lebih dari 2 kali hanya sejumlah 10 stasiun. Nilai faktor amplifikasi gelombang yang tercatat di stasiun diperkirakan tidak hanya dipengaruhi oleh karakteristik tanah permukaan namun juga dipengaruhi oleh perlakuan terhadap sensor.

\section{Ucapan Terima Kasih}

Penulis mengucapkan terima kasih kepada BMKG yang telah memberikan data mikrotremor 22 stasiun seismik yang ada di Pulau Jawa. Selain itu, ucapan terima kasih juga ditujukan kepada STMKG yang telah mendukung penulis dalam menyelesaikan penelitian ini baik secara moril maupun materiil.
[1] Trnkoczy, et al.,"Site Selection, Preparation, and Installation of Seismic Stations", edited by P. Bormann, IASPEI New Manual of Seismological Observatory Practice, Postdam, Germany, 2002.

[2] W. Partono, M. Irsyam, S.P.R. Wardani, and S. Maarif, "Kom- parasi Nilai Faktor Amplifikasi Tanah dengan Pendekatan Ssa dan Hvsr pada Wilayah Kecamatan Tembalang Kota Semarang", J. Tek., vol. 34, no. 3, pp. 141-149, 2013.

[3] S. Sungkono and B.J. Santosa, "Karakterisasi Kurva Horizontalto-Vertical Spectral Ratio: Kajian Literatur dan Pemodelan”, J. 
Neutrino, vol. 4, no. 1, 2011.

[4] Y. Wu, R.M. Allen, and C. Wu, "Revised ML Determination for Crustal Earthquakes in Taiwan”, Bull. Seism. Soc. Am., vol. 95 , no. 6, pp. 2517-2524, 2005.

[5] Y. Nakamura, "Method for Dynamic Characteristics Estimation of Subsurface Using Microtremor on the Ground Surface", Quarterly Report of RTRI, vol. 30, No. 1, pp. 25-33, 1989.

[6] J.W. Cooley and J.W. Tukey, "An algorithm for the machine calculation of complex Fourier series", Math. Of Compt., vol. 19, no. 90, pp. 297-301, 1965.

[7] SESAME, "Guidelines fr the Implementation of the H/V Spectral Ratio Technique on Ambient Vibrations: Measurements, Processing and Interpretation”, 2004. Tersedia online di :http://sesame.fp5.obs.ujf\%1 Egrenoble.fr/Delivrables/Del $\% 1 \mathrm{ED} 23 \% 1 \mathrm{EHV}$-user-guidelines.pdf, 2004
[8] K. Konno and T. Ohmachi, "Ground-Motion Characteristics Estimated from Spectral Ratio between Horizontal and Vertical Components of Microtremor", Bull. Seism.Soc. Am., vol. 88, no. 1, pp. 228-241, 1998.

[9] J. X. Zhao, et al., "Attenuation relations of strong ground motion in Japan using site classification based on predominant period", Bull. Seism.Soc. Am., vol. 96, no. 3, pp. 898-913, 2006.

[10] S. Wang, and H. Hao, "Effects of random variations of soil properties on site amplification of seismic ground motions:", Soil Dyn.and Earth. Eng., vol. 22, no. 7, pp. 551-564, 2002.

[11] D.D. Warnana, R.A.A. Soemitro, and W. Utama, "Application of microtremor HVSR method for assessing site effect in residual soil slope”, Int. J. Bas. and App. Sci., vol. 11, no. 4, pp. 100-105, 2011. 